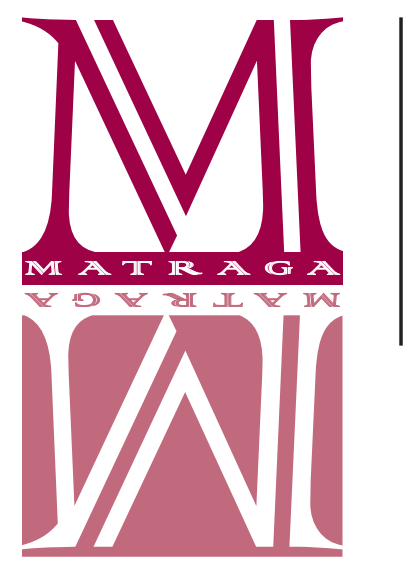

\title{
Lendo a quarentena
}

\author{
Lucas Bandeira de Melo Carvalho \\ Universidade Federal do Rio de Janeiro \\ https://orcid.org/0000-0003-3553-5892
}

\section{RESUMO}

Este artigo é uma tentativa de abordar as práticas de leitura e escrita em momentos de emergência usando como método o ensaio pessoal, isto é, uma investigação, a partir de uma experiência individual mas compartilhada, da relação entre sujeito e texto durante eventos que modificam a percepção de tempo e espaço. Parte-se dessa experiência compartilhada - a reclusão mais ou menos voluntária no primeiro semestre de 2020 em decorrência da pandemia mundial da Covid-19 - para investigar de que modo um evento como esse transforma a maneira como escolhemos e nos relacionamos com textos antigos e contemporâneos, artísticos e jornalísticos, com ênfase na leitura dos diários produzidos e publicados durante o primeiro semestre de 2020. O artigo também pretende fazer um mapeamento inicial e subjetivo dos textos testemunhais publicados sobre a pandemia. O objetivo não é construir uma tipologia atemporal das formas de leitura ou dos diários, mas descrever estratégias possíveis de leitura e escrita mediadas pela ideia de emergência.

PALAVRAS-CHAVE: Leitura; Diários; Quarentena.

\section{Reading The Quarantine}

\section{ABSTRACT}

This article is an attempt to approach reading and writing practices in times of emergency using the personal essay as a method; in other words, it is an investigation, based on an individual but shared experience, of the relationship between subject and text during events that modify the perception of time and space. Based on this shared experience - the more or less voluntary social distancing in the first half of 2020 due to the Covid-19 world pandemic -, we intend to investigate how an event like this transforms the way we choose and our relationship with old and contemporary, artistic and journalistic texts, with an emphasis on the reading of the diaries produced and published during the first semester of 2020 . The article also intends to make an initial and subjective mapping of the published testimonies on the pandemic. The objective is not to build a timeless typology of the forms of reading or a typology of the diaries, but to describe possible reading and writing strategies mediated by the idea of emergency.

KEYWORDS: Reading; Journal; Quarantine. 
1.

Neste início de maio de 2020, em que todos estão falando da mesma coisa, escrevendo sobre a mesma coisa, lendo sobre a mesma coisa, parece haver uma saturação de ensaios escritos às pressas, depoimentos que descrevem como as pessoas se adaptam ao isolamento social, previsões do futuro pós-pandemia. Não sendo alguém da área de saúde ou alguém diretamente atingido pela Covid-19, é possível falar algo que escape da banal descrição da nossa versão individual desse evento que absorve todos os outros? Por outro lado, quando todos estão falando da mesma coisa, como falar de outra coisa?

Queiramos ou não, o discurso da pandemia atravessa tudo que produzimos, todas as notícias, todos os livros que lemos, todos os artigos que escrevemos, os volumes que pegamos na estante, o filme que escolhemos no cardápio dos canais de streaming que, a fim de aplacar a angústia dos isolados - e, com isso, fidelizar uma nova clientela -, liberam por um período seus serviços de graça.

Eu mesmo faço escolhas com base na emergência - o que de certa forma faz deste um texto sem corpus, mas com "corpos", como sugeriu certa vez Roland Barthes (1984, 19). (Emergência em dois sentidos. Primeiro: pelo que se sabe até agora, a pandemia é um evento que "emerge" a partir de um conjunto complexo de fatores: capitalismo globalizado, diminuição do hábitat natural de espécies animais, centralidade econômica da China, o simples acaso. Ao mesmo tempo, é uma situação "grave e perigosa", como o dicionário define "emergência".) Como muitos leitores na quarentena, fui ler $A$ peste, de Albert Camus, que virou best seller 73 anos depois de publicado. ${ }^{1} \mathrm{O}$ livro produziu em mim, é claro, um reconhecimento. Como no romance, estamos agora obrigados a repensar nossos laços de solidariedade, ao mesmo tempo que vemos acessos de egoísmo, muitas vezes de quem ocupa lugares de liderança nos negócios e na administração pública. Além disso, o livro termina com um lembrete óbvio, mas que sempre esquecemos, talvez ofuscados pela ilusão "civilizada" de que os produtos da ação humana podem nos proteger da natureza e da história: "o bacilo da peste não morre nem desaparece nunca (...) viria talvez o dia em que, para desgraça e ensinamento dos homens, a peste acordaria os seus ratos e os mandaria morrer numa cidade feliz" (CAMUS, 2008, p. 291). Suponho que, como eu, os milhares que leem e releem o livro de Camus neste momento imaginem que estão vivendo o dia da desgraça e do ensinamento.

Para mim, no entanto, o reconhecimento falha em algum momento da leitura. Enquanto romance, $A$ peste não me disse muita coisa. A impressão mais forte que ficou não é de identificação "profética", mas de estranhamento. Depois de acompanhar na imprensa discussões sobre como os efeitos da pandemia variam de acordo com classes, raças e gêneros diferentes, ${ }^{2}$ como me identificar com um mundo homogêneo como o de A peste, sem personagens mulheres e com pouca variedade social? A peste, como a guerra (essa metáfora da "guerra" nos persegue), parecia então um assunto de homens. Além disso, há no livro de Camus uma mistura de realismo e

\footnotetext{
1 Cf, 'A PESTE' (2020). Outro impulso imediato foi ir atrás do cinema apocalíptico, como Slavoj Žižek (2020).

2 Ver, por exemplo, Corossacz (2020).
} 
didatismo que parece guiar o leitor para esse ensinamento final. É essa transparência da alegoria que me impede de levar tão a sério a analogia entre o livro e a situação que vivemos. Assistimos à construção da alegoria por meio de uma repetição mais ou menos igual de recursos em cada uma das cinco partes: uma longa abertura explicativa; uma descrição da cidade e do tempo atmosférico, cenas dos personagens - pontuadas por lugares-comuns fatalistas ("Para ser santo, é preciso viver") - e uma síntese do narrador.

A minha leitura volta-se, então, para o que está sendo escrito agora sobre a pandemia: os diários e os testemunhos. O leitor que deseja acompanhar as vidas na pandemia tem um leque bem amplo de opções. Cito alguns que li recentemente: o diário do escritor João Paulo Cuenca (2020), publicado na revista Quatro cinco um; o do professor Francisco Foot Hardman (2020), publicado no Jornal da Unicamp; as "cartas contra a separação" no site da revista e-flux (LU et al, 2020); os "Diários do isolamento" de escritores da Companhia das Letras, publicados no blog da editora; ${ }^{3}$ podcasts, como o da personagem Laurinha Lero, na revista Gama (O DIÁRIO DE QUARENTENA, 2020). Além disso, jornais como O Estado de S. Paulo (GUERRA, 2020) e A Folha de S. Paulo (BRAGATTO, 2020) e revistas como Piauí (CARVALHO, 2020) publicaram diários mais informativos, a fim de "humanizar", como diz o jargão, a cobertura. Há ainda quem tire fotos diárias da janela do prédio, documentando a mudança lenta mas diária de um tempo estagnado (mas não parado), e publique no Instagram. E há os incontáveis perfis, mais ou menos lidos, inundando as redes sociais de depoimentos sobre a sua quarentena. Em graus variados, há neles o sentido de urgência e a ambiguidade entre informação e banalidade que me parece uma característica quase inevitável do discurso da emergência.

Essa profusão de relatos em primeira pessoa tem três efeitos em mim. Primeiro, muitas vezes me informa. Saber como funcionam as restrições na China, como explica a brasileira Andrea Micherif no podcast Foro de Teresina, da revista Piauí, me ajuda a formar uma ideia menos incompleta de quais medidas o mundo está adotando para diminuir os efeitos da pandemia; ouvir médicos e enfermeiros do Instituto Emílio Ribas, que concentra grande parte dos casos graves da Covid-19 em São Paulo, me ajuda a entender a natureza da doença (FORO DE TERESINA \#94, 2020; CAFÉ DA MANHÃ, 2020). Num momento em que muitas autoridades parecem mais desinformar do que informar - como ocorre no debate sobre remédios antivirais -, eu sinto essa necessidade de informação "de primeira mão". Elas de certa forma me protegem, justificam a minha quarentena, reforçam minha confiança em certo consenso racional que me faz acreditar que nem tudo está perdido. Num momento em que o presidente da república participa de uma manifestação contra a quarentena e a favor de um golpe militar (PORTINARI E MENDES, 2020), eu preciso me convencer de que em algum lugar do mundo há pessoas - governantes, médicos - que têm cautela diante de uma doença de características inéditas.

O segundo efeito da leitura diária desses relatos é o desejo de escrever. No meio do fluxo incontrolável de depoimentos sobre a pandemia, sinto que preciso, eu também, fincar uma estaca e falar: é aqui que eu me encontro no meio da emergência; este é o meu lugar; é daqui que eu falo.

\footnotetext{
${ }^{3}$ As contribuições estão disponíveis em http://www.blogdacompanhia.com.br/secoes/visualizar/Diarios-do-isolamento.
} 
Como é a minha quarentena? Quando vi a foto de Victor Moriyama das janelas do Copan iluminadas na pandemia, publicada em página dupla no New York Times (CAPELHUCHNIK, 2020), não pude deixar de pensar no meu antigo hábito de espiar os vizinhos, costume que carrego comigo para todos os apartamentos em que moro e que ganhou novos contornos em tempo de isolamento. Vendo essa imagem, penso em como as janelas viraram canais de observação e exibição. Vão se estabelecendo rituais que podem ajudar a sobreviver ou que podem nos fazer abandonar a esperança. No meu quarteirão da rua Raul Pompeia, às seis da tarde, alguém põe a "Ave Maria" de Schubert para tocar, seguida por aplausos dos vizinhos. Esse costuma ser o primeiro baque na minha esperança. Não gosto da música, não há nada para aplaudir. Às oito e meia, batem panelas contra o governo, mas aqui há outro ritual: o embate aos gritos entre vizinhos que apoiam o presidente e os críticos, entre os quais me incluo.

Para mim, porém, o mais curioso é como a Raul Pompeia da quarentena virou uma espécie de rua de cidade pequena. O isolamento social transformou o bairro de Copacabana, com sua absurda densidade demográfica, em um mosaico de becos interioranos. Cada barulho na rua é seguido por dezenas de cabeças despontando na janela. A minha Copacabana de 2020 não tem nada a ver com a cidade dos vícios de João Antônio. ${ }^{4}$

Paro aqui de descrever meu isolamento. O desejo de escrever esbarra, para mim, no terceiro efeito: a banalidade, que me parece mais absurda quando há gente morrendo e há pessoas na linha de frente (de novo a metáfora bélica...). Lembro de novo do final de A peste, quando o narrador, Dr. Rieux, diz que sua função é "depor a favor dessas vítimas da peste" (CAMUS, 2008, p. 290). O depoimento do médico-narrador, no entanto, está ali para substituir outro: o depoimento das vítimas da ocupação nazista na França. ${ }^{5}$ (Lembro que $A$ peste foi lançado na França no mesmo ano do incrível depoimento literário A espécie humana, de Robert Antelme, sobrevivente que foi preso em Buchenwald e Gandersheim.) Eu me pergunto se meu diário da banalidade não serviria também para substituir outro depoimento. Tudo que poderia fazer é meu depoimento "à janela do apartamento" enquanto "podemos beber honradamente nossa cerveja" - como escreveu Drummond, que morou aqui perto, na Joaquim Nabuco e na Conselheiro Lafaiete, e que tantas vezes escreveu sobre essa sensação de estar longe dos acontecimentos. Enquanto bebemos nossa cerveja, a história ocorre lá fora, nos hospitais e nos gabinetes, nas casas cujos moradores são obrigados a sair para trabalhar, nos ônibus e vagões de metrô que se enchem ou esvaziam de acordo com decisões "vinculantes" (de patrões, reitores, prefeitos, governadores, presidentes) e individuais (influenciadas por articulistas e políticos negacionistas e pelas redes sociais).

Tento uma alternativa: falar da minha leitura. As leituras que buscam analogias (A peste), as que buscam depoimentos (os diários do front), as que buscam correlatos a mim (como o diário de escritores). Há, ainda, uma quarta categoria: as que buscam me afastar do presente e me recolocar no campo do trabalho. Reli clássicos (Werther), li outros pela primeira vez (O som e a fúria), tentei me colocar mais ou menos em dia com a literatura contemporânea (li Pontos de fuga, do Milton Hatoun; retomo Dramaturgia negra, organizado por Eugênio Lima e Julio Lu-

\footnotetext{
${ }^{4}$ Penso aqui no ensaio de Beatriz Resende (2008).

${ }^{5}$ Sobre A peste como alegoria da ocupação, ver Judt (2001).
} 
demir). Todos, no entanto, são lidos a partir dessa suspensão temporal. São leituras que servirão para algo no futuro, e sua contemporaneidade foi jogada ou um pouco para trás ou foi adiada. A literatura contemporânea lançada até fevereiro de repente parece não exatamente velha, mas não contemporânea. ("Nada parece tão antigo quanto o passado recente", escreve João Paulo Cuenca em seu diário, mas já lemos essa frase antes.) Isso porque fazia parte de um sistema cadernos culturais, livrarias, lançamentos, encontros, aulas - que está paralisado. Outros livros, porém, são lidos para informar o trabalho futuro - aulas, artigos, pesquisas -, que me parece menos urgente diante do que está acontecendo.

Há, portanto, a leitura analógica, a leitura informativa, a leitura projetiva (ou narcisista), a leitura laboral, todas elas ancoradas na inevitabilidade do evento da pandemia.

\section{2.}

Falar da leitura é uma maneira de inverter a paralisia e tentar transformar em laboral as leituras "emergenciais".

Fui primeiro buscar analogias em diários, depoimentos e correspondências de outras épocas. Um pouco ao acaso, consultei alguns livros, até me deter no diário de Sartre durante a Segunda Guerra Mundial. Paro num comentário que ele escreveu quando relia seus cadernos: "Eu fazia uma guerra à minha imagem" (SARTRE, 2005, p. 9). Olhando para trás, ele entendia como filtrava os acontecimentos ao redor para adequar a um imaginário estoico, ou mesmo como usava os acontecimentos para falar de si. Lendo o diário, porém, percebemos como o escritor também fala de uma relação com os acontecimentos. Em 18 de setembro de 1939 ele escreve: "A guerra fantasma. Uma guerra à maneira de Kafka. Não chego a 'senti-la', ela esquiva-se de mim. Os comunicados não mencionam nossas perdas. Não vi nenhum ferido" (idem, p. 34-35). É fácil uma analogia aqui. O diário hoje não é uma forma de fazer uma pandemia à nossa imagem? Não é uma maneira de conseguir elaborar um acontecimento que, como a guerra para Sartre, continua sendo um fantasma? Sabemos que ele existe, mas seus contornos são incertos: são quantas mortes, qual o tamanho da pandemia?

Encontro ainda outro tipo de elaboração do acontecimento nos diários. Lembro de uma frase de Kafka (1975, p. 404), anotada em 23 de janeiro de 1922: "Aceite seus sintomas, não reclame deles; submerja no seu próprio sofrimento" (tradução minha). Essa frase funciona como um aforismo: serve para todo tipo de sintomas: uma doença, a opressão da guerra ou a inquietude (que é o estado que Kafka descreve antes de anotar a frase). Nesses diários antigos, encontro o caráter inevitável do evento: não tem como escapar da pandemia, como não tem como escapar da guerra ou da doença, e o que se pode fazer é submergir nela, isto é, aceitar uma situação inevitável de maneira consciente, não passiva. Submergir.

Mas dá mesmo para submergir? Volto a Sartre: a "guerra não é o cólera, mas um fato humano criado por vontades livres. É impossível considerá-lo como uma doença dolorosa contra a qual é indispensável aplicar o estoicismo simples" (SARTRE, 2005, p. 21). A metáfora da guerra cansa, mas ainda assim volto a ela. O que é a Covid-19? É uma doença contagiosa. Porém, não é um fato humano criado por vontades livres a maneira como os países reagem à pandemia? 
Há, no entanto, uma diferença grande entre o diário de Sartre e os diários da pandemia que leio durante a quarentena. Ao contrário dos diários antigos, que percorro como a construção já terminada de uma figura (a figura do intelectual durante a guerra, por exemplo), os contemporâneos me chegam como cartas públicas sem destinatário. Há algo nessa forma de escrita que me soa como um tipo de jornalismo arcaico, antes do surgimento da reportagem. É como se lêssemos o "correio" público enviado de algum lugar. O correspondente do jornal antigo era aquele que enviava cartas, em que contava em primeira mão algo a que assistira ou resumia o noticiário que chegava à cidade onde morava. $\mathrm{O}$ interessante aqui é a importância do lugar de onde se escreve. Leio um exemplo um pouco tardio dessas correspondências: as "Cartas da Inglaterra", de Rui Barbosa, enviadas para o Jornal do Commercio. Numa delas, de 1895, ele resume para o público brasileiro o Caso Dreyfus, mas não como se pudesse relatar a totalidade do fato, e sim a partir da maneira como ele é interpretado pelo noticiário inglês (BARBOSA, 1946). Na mesma época, Euclides da Cunha enviava para o jornal O Estado de S. Paulo suas reportagens sobre a Guerra de Canudos (1896-1897). A primeira reportagem começa da seguinte maneira:

\footnotetext{
Depois de quatro longos dias de verdadeira tortura subo pela última vez à tolda do vapor na entrada belíssima e arrebatadora da Bahia.

Não descreverei os incidentes da viagem, vistos todos através de inconcebível mal-estar (...)

Escrevo rapidamente, direi mesmo vertiginosamente, acotovelado todo instante por passageiros que irradiam em todas as direções (...). (CUNHA, 2009, p. 505)
}

Esses parágrafos repetem quase palavra por palavra as anotações do "Diário de uma expedição" (idem, p. 605), os cadernos de campo do repórter-escritor.

Como leitor do diário e da reportagem de Euclides, me pergunto se, nesse jornalismo testemunhal, há um complemento "realista" à carga informativa. "Estive lá", diz a primeira pessoa. Mas o que é esse "lá"? "Lá" é onde está o tempo do acontecimento, enquanto "aqui" está o tempo da leitura. Volto à leitura analógica de Sartre. Em 2 de fevereiro de 1940, ele compara o "tempo trivial e amorfo" de todos os dias com o "lá" "das músicas e da aventura" (SARTRE, 2005, p. 425).

O que é, para mim, esse "lá" do acontecimento, que certamente não está na leitura projetiva-narcisista, mas na informativa? A maneira como tenho experimentado o tempo desde o início da quarentena - e imagino que outros tenham uma experiência semelhante - é de um descolamento entre dois tipos de temporalidade. Por um lado, há uma espécie de tempo circular, em suspenso, em que nada de fato acontece. Todos os dias transcorrem da mesma maneira (não há sábados e domingos), os prazos mais importantes foram adiados, os planos de futuro foram cancelados ou esperam momento "oportuno". Ao mesmo tempo, a história parece estar transcorrendo diante de mim na tela do computador ou do celular em alta velocidade. A leitura do diário de quem antes de mim esteve "lá", no tempo do acontecimento - onde a pandemia chegou antes -, é uma maneira de me ligar ao transcorrer dos dias, de escapar da circularidade do tempo "daqui".

Por fim, se leio diários e depoimentos para acessar o "lá" que me permite sentir que estou dentro dos acontecimentos, também leio aquilo que me permite encontrar um "aqui" semelhante ao meu, o do tempo da leitura, o "tempo suspenso". O "tempo suspenso" não decorre necessariamente da falta de atividade. Por mais que fique em frente ao computador trabalhando, 
o tempo ainda é vivido como em suspensão. Não se trata de produtividade, mas de duração. (Leio a expressão “tempo suspenso" nos Diários de Emilio Renzi, de Ricardo Piglia [2019, p. 62], quando o narrador fala dos momentos de Cesare Pavese antes do suicídio.)

É essa identidade que justifica para mim o exercício narcisista da leitura dos diários banais, distantes do "lá" do acontecimento. Michel Leiris escreveu em "Da literatura como tauromaquia", de 1946, que "no fundo de toda confissão há o desejo de ser absolvido" (LEIRIS, 2003, p. 18), mas talvez a leitura projetiva na verdade funcione não para absolver o escritor, mas para nos absolvermos como leitores. Confirmo que há outras pessoas como eu que não conseguem se descolar do evento pandêmico, embora não possam informar nada, a não ser dar a "sua imagem" do evento. O que justifica a leitura do que há de mais banal é podermos nela identificar o nosso tempo suspenso. O que permite a projeção é justamente a banalidade: na última ida ao supermercado do escritor antes de se isolar, vejo a minha última ida ao supermercado antes de me isolar; na fotografia das janelas acesas, vejo as do prédio que vejo da janela.

Como leitor, fico entre o "lá" e o "aqui". É essa ambivalência entre tempos e espaços próximos e distantes do acontecimento que encontro em alguns dos depoimentos de escritores publicados na revista Piauí de abril: por um lado, descrevem sua versão da pandemia; por outro, fazem um gesto em direção ao palco dos acontecimentos ("volto a pensar nas famílias pobres que se espremem em cubículos da periferia e das favelas", escreve Maria Esther Maciel [2020, p. 10]; "Penso em quantos morrerão" e "Penso na Itália", escreve Ana Paula Maia [2020, p. 11]; "Torço, sem parar, para que fiquem todos bem", escreve Carol Bensimon [2020, p.12]). ${ }^{6}$ Como eles, preciso, na minha leitura de quarentena, tentar me colocar no lugar do outro e, ao mesmo tempo, ancorar o eu que permanece distante do acontecimento.

\section{3.}

É impossível acompanhar todos os diários publicados nessa quarentena. Também me parece inútil, no momento, tentar classificar ou definir apressadamente os tipos - por isso prefiro classificar minha leitura. Escolho, para terminar, dois diários que me parecem ilustrativos da minha leitura informativa e da minha leitura projetiva-narcisista.

O diário de uma família chinesa em Pequim, publicado pela revista e-flux, começa já afirmando-se como um elo de uma corrente de diários cuja função é informar. O casal diz ter começado a aprender sobre o vírus lendo diários de dois escritores de Wuhan, na província de Hubei, primeira região a entrar em quarentena na China, e suas anotações devem ter a mesma função. "Acreditamos que escrever e compartilhar nossa experiência pode tanto nos ajudar a desenvolver uma compreensão melhor de nossa experiência quanto, talvez, conectar muitos de nós que ao mesmo tempo temem a situação e estão determinados a entendê-la." E a primeira coisa que aprendem é que "experiências passadas não se aplicam" a esta.

O mais interessante do diário dessa família, formada pela curadora Carol Yinghua $\mathrm{Lu}$ (2020), pelo artista Liu Ding e pelo filho deles, Liu Quingshuo, é o arranjo que fazem de fragmentos de

\footnotetext{
${ }^{6}$ Os textos fazem parte da seção "Quarentena", Piauí, abril de 2000, p. 8-12.
} 
vozes que circulam pelas redes sociais do país. No dia 31 de março, por exemplo, eles publicam no diário um GIF que traduz a expressão "shuai guo", que significa “jogar panelas". O GIF viralizou como síntese da disputa entre autoridades nacionais e locais chinesas para estabelecer de quem é a responsabilidade pela demora inicial em controlar a epidemia. Em seguida, há um curto vídeo de dois membros de um grupo de resgate que vão prestar homenagem a Li Wenliang, um dos primeiros médicos a notar a circulação do novo vírus. Depois, outro vídeo, em que uma mulher bate um gongo na pequena varanda do prédio, tentando pedir um leito de hospital para a mãe doente (o post informa que ela consegue o leito). O vídeo seguinte é tirado de outra rede social, TikTok, e mostra o porta-malas de um carro, parado desde o início da quarentena, em que estaria nascendo mato. Os escritores do diário comentam que não sabem se o vídeo é real, mas a "informação" que o vídeo passa não é essa: o que o vídeo nos conta é como circulam pelas redes sociais na China imagens do tempo da quarentena, em que se embaralham velocidade e imobilidade, natureza e cultura. Há ainda, no post, um rap feito com colagens de mensagens de voz indignadas enviadas por uma mulher de Wuhan para um grupo de WeChat, o WhatsApp chinês. E, por fim, dois vídeos curtos que curiosamente conversam entre si: num deles, vemos ondas criadas por uma ventania no lago Kunming, no Palácio de Verão, no dia 18 de março; no outro, vemos uma multidão na província de Jiangxi que, com medo de contaminação, tenta impedir que pessoas vindas de Hubei cruzem a fronteira entre as províncias.

O que essa entrada do diário mostra, com uma concisão interessante, é como essa profusão de testemunhos em texto, áudio e vídeo forma um coro de vozes que produzem uma imagem diferente daquela dos meios de comunicação e dos comunicados oficiais. Essas vozes circulam pelas redes sociais e servem para informar aquilo que uma reportagem ou uma estatística não consegue: como aqueles ali vivem a pandemia?; de que maneira essa experiência é diferente da minha agora? O importante não é apenas saber como a polícia chinesa impede que se vá à rua, ou como está o atendimento hospitalar na Itália, mas saber de que maneira pessoas tão distantes de mim estão conseguindo simbolizar essa irrupção tão violenta do real, como estão conseguindo dar forma à experiência de um acontecimento inesperado. Um GIF que sintetiza a impotência do indivíduo diante do poder dos gabinetes que decidem as políticas de enfrentamento da pandemia (gabinetes que jogam panelas globalmente). A tocadora de gongo que pede saúde, como os batedores de panela das janelas brasileiras. O rap - gênero tão político - que transforma a voz anônima na voz da revolta coletiva. A montagem de duas imagens - a onda da multidão e a onda da natureza - que produz um choque dialético entre ação e matéria e nos lembra que não podemos separar o natural do humano.

Dos diários que leio projetivamente, o que mais me interessou até agora são os quadros de Fabio Moon, publicados no blog da editora Companhia das Letras, talvez porque me pareçam o que mais claramente trabalha a matéria propriamente artística. Como em outros diários de escritores, professores, jornalistas, eu me reconheço em várias situações figuradas ali. Como o personagem de Moon, ${ }^{7}$ eu tenho tentado fazer ioga copiando as posições de lives do Instagram;

\footnotetext{
7 Diários do Isolamento, Fábio Moon, dia 24, 15 de abril de 2020. Imagem integral disponível em: <http://www.blogdacompanhia.com.br/conteudos/visualizar/Diarios-do-isolamento-24-Fabio-Moon>.
} 
quando vejo séries e filmes na TV, eu também me faço a pergunta absurda: por que aquelas pessoas não estão usando máscara?; como ele, tenho sonhado mais do que antes da quarentena; e também tenho a sensação de não estar fazendo nada. ${ }^{8}$

Há nesses quadros (como nos de outros quadrinistas brasileiros) alguma coisa de crônica, da capacidade de escrever (ou desenhar bem) não apenas sobre o banal, mas sobre o contingente e fugaz, que é eficaz numa situação em que só conseguimos falar do contingente. Como lembra Beatriz Resende (2016, p. 55), a crônica lida sempre com a contingência, com as contradições do que é dito às pressas, com uma encenação do eu e de proximidade com o leitor, e também com a "ligação direta com o veículo que a divulga". Por não ser feita para durar, a crônica foge do monumental, mas, justamente por tratar do que é mais banal, "fica perto de nós" e "ensina a conviver intimamente com a palavra", como escreveu Antonio Candido (1992, p. 13 e 15).

Quando olho a página desenhada por Moon de um café da manhã na quarentena (http:// www.blogdacompanhia.com.br/conteudos/visualizar/Diarios-do-isolamento-24-Fabio-Moon), por exemplo, meu olhar é atraído pelos coelhos. Reconheço a situação vivida por aquela versão ficcional do autor como uma situação perto de mim - a refeição interrompida por mensagens no celular que muitas vezes trazem notícias horríveis -, mas é a sombra no dorso do coelho e a posição de suas patas que me fazem por um momento contemplar "intimamente" a mancha de pixels na tela do meu computador. Embora haja momentos de reflexão nos quadrinhos, o que me atrai é como eles carregam caráter duplo da crônica e do diário: apesar de contingente, aquilo permanece pela forma “justa”, para usar o adjetivo flaubertiano. É como se eu conseguisse lendo o diário ilustrado - o que não ocorre na leitura de outros diários de escritores - me dividir: um lado reconhecimento narcisista, outro lado contemplação.

Também fica mais claro, nos quadros de Moon, como esses diários da quarentena que estamos lendo têm a curiosa característica de serem "diários para publicação", diretamente ligados aos veículos que os divulgam, às vezes encomendados. São textos e imagens em primeira pessoa que encenam a escrita íntima, mas são desde o início pensados como escritas para o outro. Claro, podemos falar isso de toda escrita autobiográfica. Como Leiris (2003, p. 19-20) comentou sobre seu $A$ idade viril, a escrita autobiográfica é ao mesmo tempo um ato "em relação a mim próprio", um ato "em relação a outrem" e um ato "no plano literário" de negação do romanesco.

Perto de concluir o texto, vejo que só consigo reafirmar o que justifica minhas leituras: a necessidade de saber onde eu me encontro no meio da emergência, reafirmar como minha relação com a pandemia é marcada pelo lugar onde estou. Enquanto o diário de Carol Yinghua Lu e Liu Ding me inunda de vozes que me jogam na diferença, o diário ilustrado de Moon me oferece uma forma bela para uma experiência em que me reconheço: a da classe média brasileira isolada. A leitura dessa explosão de depoimentos, diários e postagens de redes sociais serve para nos colocar no mundo, para nos lembrar que fazemos parte do mesmo universo de onde partem as vozes em que reconhecemos experiências mais ou menos próximas da nossa. Serve, enfim, para aproximar o lá e o aqui.

\footnotetext{
8 Diários do Isolamento, Fábio Moon, dia 38, 29 de abril de 2020. Imagem integral disponível em <http://www.blogdacompanhia.com.br/conteudos/visualizar/Diarios-do-isolamento-38-Fabio-Moon>.
} 


\section{REFERÊNCIAS}

'A PESTE', de Albert Camus, vira best-seller em meio à pandemia de coronavírus. Folha de S. Paulo, São Paulo, 12 mar. 2020. Disponível em: <https://www1.folha.uol.com.br/ilustrada/2020/03/a-peste-de-albert-camus-vira-best-seller-em-meio-a-pandemia-de-coronavirus.shtml>. Acesso em: 24 maio 2020.

BARBOSA, Ruy. Cartas da Inglaterra. Obras completas, v. XXIII, t. I. Rio de Janeiro: Ministério da Educação e Saúde, 1946.

BARTHES, Roland. A câmara clara: notas sobre a fotografia. Trad. Júlio Castañon Guimarães. Rio de Janeiro: Nova Fronteira, 1984.

BENSIMON, Carol. Uma cabana na floresta. Piauí, ed. 163, abr. 2000. Quarentena, p. 11-12.

BRAGATTO, Susana. Diário de confinamento. Folha de S. Paulo, 16 mar.-23 maio 2020. Disponível em: < https://www1.folha.uol.com.br/mundo/diario-de-confinamento/2020/\#60>. Acesso em: 24 maio 2020.

CAFÉ DA MANHÃ. Uma repórter na UTI da Covid-19. Locutores: Rodrigo Vizeu e Magê Flores. São Paulo: Folha de S. Paulo, 20 abr. 2020. Podcast. Disponível em: <https://www1.folha.uol.com.br/podcasts/2020/04/ reporter-relata-rotina-de-uti-destinada-a-pacientes-de-covid-19-ouca.shtml $>$. Acesso em: 24 maio 2020.

CAMUS, Albert. A peste. Trad. Valerie Rumjanek. Rio de Janeiro: BestBolso, 2008.

CANDIDO, Antonio. A vida ao rés-do-chão. In: CANDIDO, Antonio et al. A crônica: o gênero, sua fixação e suas transformações no Brasil. Campinas: Ed. Unicamp; Rio de Janeiro: Fundação Casa de Rui Barbosa, p. 13-22, 1992.

CAPELHUCHNIK, Laura. Como é fotografar uma crise. Revista Gama, 19 maio 2020. Disponível em: < https://gamarevista.com.br/conversas/como-e-fotografar-uma-crise/>. Acesso em: 24 maio 2020.

CARVALHO, Higor. No coração do medo. Piauí, ed. 162, mar. 2020. Disponível em: < https://piaui.folha.uol. com.br/materia/no-coracao-do-medo/>. Acesso em: 24 maio 2020.

COROSSACZ, Valeria Ribeiro. Minha cidade: espaço e tempo coletivos na itália do coronavírus. Revista Z Cultural, ano XV, n.1, $1^{\circ}$ semestre 2020. Disponível em: < http://revistazcultural.pacc.ufrj.br/minha-cidade-espaco-e-tempo-coletivos-na-italia-do-coronavirus/>. Acesso em: 24 maio 2020.

CUENCA, João Paulo. Diário de São Paulo (ou Diário da Quarentena). Quatro cinco um, 21 abr. 2020. Disponível em: <https://www.quatrocincoum.com.br/br/artigos/c/diario-de-sao-paulo-ou-diario-da-quarentena>. Acesso em: 24 maio 2020.

CUNHA, Euclides da. Canudos: diário de uma expedição. In: Obra Completa, v. 2.2 ed. Org. Paulo Roberto Pereira. Rio de Janeiro: Nova Aguilar, p. 495-601, 2009.

FORO DE TERESINA \#94. A subnotificação do vírus, Bolsonaro acuado e a economia desgovernada. Locutores: Fernando de Barros e Silva, Malu Gaspar, José Roberto de Toledo e Bernardo Esteves. Rio de Janeiro: Rádio Novelo/Piauí, 2 abr. 2020. Podcast. Disponível em: <https://piaui.folha.uol.com.br/foro-de-teresina-94-subnotificacao-do-virus-bolsonaro-acuado-e-economia-deriva/>. Acesso em: 24 maio 2020.

GUERRA, Caleb. Diário da quarentena, parte 1: 'Não consigo esquecer a parte da minha vida que deixei em Wuhan'. O Estado de S. Paulo, 11 fev. 2020. Disponível em: <https://www.msn.com/pt-br/noticias/brasil/ di\%C3\%A1rio-da-quarentena-parte-1-n\%C3\%A3o-consigo-esquecer-a-parte-da-minha-vida-que-deixei-em-wuhan/ar-BBZTbql>. Acesso em: 24 maio 2020. 
JUDT, Tony. A hero for our times. The Guardian, 17 nov. 2001. Disponível em: <https://www.theguardian. com/books/2001/nov/17/albertcamus >. Acesso em: 24 maio 2020.

HARDMAN, Francisco Foot. Diário em Pequim. Jornal da Unicamp, 7 fev.-15 maio 2020. Disponível em: <https://www.unicamp.br/unicamp/ju/especial/diario-em-pequim>. Acesso em: 16 ago. 2001.

KAFKA, Franz. The Diaries: 1910-1923. Trad. Joseph Kresh, Martin Greenberg e Hannah Arendt. Nova York: Schoken, 1975.

LEIRIS, Michel. Da literatura como tauromaquia. In: A idade viril. Trad. Paulo Neves. São Paulo: Cosac \& Naify, 2003.

LU, Carol Yinghua et al. Letters against Separation on e-flux conversations. e-flux, 4 abr. 2020. Disponível em: <https://www.e-flux.com/announcements/325621/letters-against-separation-on-e-flux-conversations/>. Acesso em: 24 abr. 2020.

MACIEL, Maria Esther. A cidade irreal. Piauí, ed. 163, p. 10-11, abr. 2000.

MAIA, Ana Paula. Café Terrace at Night. Piauí, ed. 163, abr. 2000. Quarentena, p. 11.

MOON, Fábio. Diário do Isolamento, dia 24. 15 abr. 2020. 2 fotografia. 500 x 375 pixels. Disponível em: <http://www.blogdacompanhia.com.br/conteudos/visualizar/Diarios-do-isolamento-24-Fabio-Moon>. Acesso em: 24 maio 2020.

MOON, Fábio. Diário do Isolamento, dia 38. 15 abr. 2020. 2 fotografia. 500 x 375 pixels. Disponível em: <http://www.blogdacompanhia.com.br/conteudos/visualizar/Diarios-do-isolamento-38-Fabio-Moon>. Acesso em: 24 maio 2020.

O DIÁRIO DE QUARENTENA da DJ Laurinha Lero. Locutora: Laurinha Lero. Revista Gama, 2 abr. 2020. Podcast. Disponível em: <https://gamarevista.com.br/sociedade/diario-da-quarentena/o-diario-de-quarentena-da-dj-laurinha-lero/>. Acesso em: 24 abr. 2020.

PIGLIA, Ricardo. Os anos felizes: Os diários de Emilio Renzi. Trad. Sérgio Molina. São Paulo: Todavia, 2019. PORTINARI, Natália; MENDES, Adriana. Bolsonaro vai a ato com aglomeração de manifestantes e pedidos de intervenção militar. O Globo, 19 abr. 2020. Disponível em: <https://oglobo.globo.com/brasil/bolsonaro-vai-ato-com-aglomeracao-de-manifestantes-pedidos-de-intervencao-militar-24382154>. Acesso em: 16 ago. 2001

RESENDE, Beatriz. Ai de mim, Copacabana: A cidade dos vícios e os vícios da cidade. In: MARGATO, Izabel; GOMES, Renato Cordeiro. Espécies de espaço: territorialidades, literatura, mídia. Belo Horizonte: Editora UFMG, p. 197-210, 2008.

RESENDE, Beatriz. Lima Barreto e Rio de Janeiro em fragmentos. 2 ed. rev. Belo Horizonte: Autêntica, 2016.

SARTRE, Jean-Paul. Diário de uma guerra estranha. 2 ed. Trad. Aulyde Soares Rodrigues e Guilherme João de Freittas Teixeira. Rio de Janeiro: Nova Fronteira, 2005.

ŽIŽEK, Slavoj. Mundo ameaçado por coronavírus não se parece com filmes apocalípticos de Hollywood, diz Zizek. Folha de S. Paulo, São Paulo, 21 abr. 2020. Ilustríssima. Disponível em: $<$ https://www1.folha.uol.com. br/ilustrissima/2020/04/mundo-ameacado-por-coronavirus-nao-se-parece-com-filmes-apocalipticos-de-hollywood-diz-zizek.shtml>. Acesso em: 24 maio 2020. 